\title{
In vivo and in vitro effects of glucocorticoids on lectin-induced blastogenesis in atopic dermatitis
}

\author{
M. Rupprecht ${ }^{1}$, R. Rupprecht ${ }^{2}$, N. Wodarz ${ }^{3}$, H. U. Braner ${ }^{3}$, J. Kornhuber ${ }^{3}$, H. U. Koch ${ }^{1}$, P. Riederer ${ }^{3}$, \\ and O.P. Hornstein ${ }^{1}$ \\ 1 Department of Dermatology, University of Erlangen-Nürnberg, Hartmannstrasse 14, W-8520 Erlangen, Federal Republic of Germany \\ 2 Max Planck-Institute of Psychiatry, Munich, FRG \\ 3 Department of Psychiatry, University of Würzburg, Würzburg, FRG
}

Received October 20, 1990

Summary. The effects of glucocorticoids administered in vivo and in vitro on lectin-induced proliferation of lymphocytes sampled from venous blood were investigated in patients with atopic dermatitis $(\mathrm{AD})$ and in normal controls. Stimulation by concanavalin A (Con A), phytohaemagglutinin A (PHA) and pokeweed mitogen (PWM) in patients and controls did not differ significantly under baseline conditions. After in vivo administration of methylprednisolone the decline of Con A-induced blastogenesis of leucocytes was similar in both groups, whereas PHA stimulation caused a significant reduction in the controls only. In vitro addition of different dexamethasone concentrations had a pronounced suppressive effect on Con A- and PHAinduced blastogenesis in both groups, whereas PWM stimulation was unaffected. Pretreatment in vivo with methylprednisolone further decreased the suppression of the Con A and PHA lymphocyte proliferation rate by dexamethasone added in vitro in controls but not in patients. With regard to B-cell proliferation generated by PWM, no consistent glucocorticoid effect could be observed. The impaired effect on lymphocyte blastogenesis of glucocorticoids administered in vivo, in contrast to a normal in vitro reaction to dexamethasone, together with recent findings of an altered glucocorticoid receptor pharmacology in $A D$, points to a decreased biological in vivo efficiency of methylprednisolone in atopic dermatitis.

Key words: Lectins - Glucocorticoids - Atopic dermatitis

Atopic dermatitis (AD) is accompanied by a variety of disturbed immune $[19,25,29]$, hormonal $[17,21]$ and even psychological [11] factors. In particular, a decrease in suppressors cells $[1,22]$ as well as normal rates of $B$ lymphocytes have been noted $[26,30,32]$. However, some

Offprint requests to: $\mathrm{M}$. Rupprecht authors have reported normal $\mathrm{T}$ cells and elevated $\mathrm{B}$ cells in atopic dermatitis $[6,12]$.

Results of studies evaluating lymphocyte response in $\mathrm{AD}$ patients to different mitogens are variable. Hyporesponsiveness of $\mathrm{T}$ - and $\mathrm{B}$-cell proliferation following stimulation with pokeweed mitogen (PWM), concanavalin $\mathrm{A}$ (Con $\mathrm{A}$ ) or phytohaemagglutinin $\mathrm{A}$ (PHA) [5, 18, $20,26,29]$ has been reported as well as normal Con A-, PHA- and PWM-induced lymphocyte blastogenesis [13, $23,32]$. Glucocorticoids inhibit lymphocyte proliferation $[8,28]$ by cytokinetic mechanisms [24] and affect the number of subpopulations of circulating lymphocytes by inducing a redistribution of intravasal cells to other lymphoid compartments, e.g. to the bone marrow $[8,9]$. Moreover, glucocorticoids have been shown to inhibit interleukin-1 (IL-1) [31] and interleukin-2 (IL-2) [4] production leading to impaired lectin-induced blastogenesis $[8,18]$. T-cell proliferation generated by Con A $[8,10]$ and PHA $[8,16,34]$ is suppressible by glucocorticoids in vivo and in vitro. However, PWM induced B-cell proliferation is relatively resistant to glucocorticoids $[2,15]$.

In view of the numerous effects of glucocorticoids on the immune system and their frequent use in the treatment of $\mathrm{AD}$, the present study was designed to evaluate the effect of glucocorticoids, administered in vivo and in vitro, on the characteristics of lymphocyte proliferation under lectin-stimulated conditions in AD compared with healthy controls.

Materials and methods

\section{Subjects}

Hospitalized patients ( 3 men and 8 women) suffering from $\mathrm{AD}$ and healthy controls ( 3 men, 7 women), with no history of asthma, hay fever or AD, participated in the study on a voluntary basis having given informed consent. Their mean age was $22.2 \pm 5.4$ years and $24.3 \pm 3.7$ years, respectively. All participants were withdrawn from any systemic therapy with corticoids or ACTH at least 2 months prior to the study. Medication, if any, with beta-blocking and/or sleep-inducing drugs was stopped at least 3 days before entering the 
DOSE RESPONSE CURVE PATIENTS

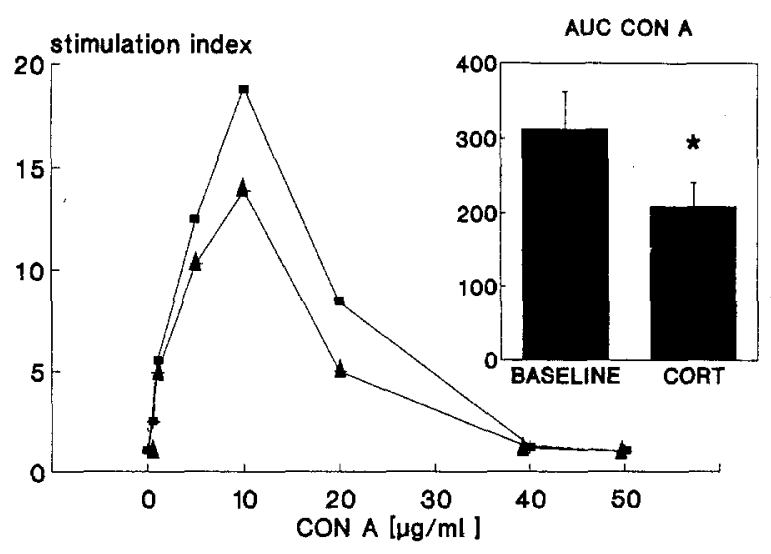

DOSE RESPONSE CURVE CONTROLS

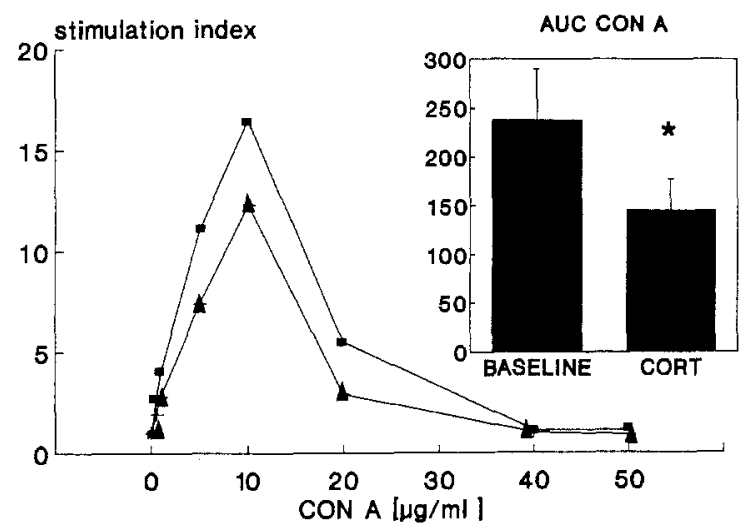

Fig. 1. Mean dose - response curves and AUC for Con A-generated lymphocyte proliferation in patients with $\mathrm{AD}$ and in normal controls under baseline conditions ( $\boldsymbol{E})$ and methylprednisolone treatment $(\boldsymbol{A})$. SEM are omitted for reasons of presentation. The inset shows the mean \pm SEM AUC for the baseline (BASELINE) and steroidtreated $(C O R T)$ condition in $\mu \mathrm{g} / \mathrm{ml}$. The difference between baseline and methylprednisolone treatment is significant $(p<0.04)$ in both patients and controls

study. Cutaneous lesions of AD were treated only with corticoidfree ointments for at least 1 week prior to and during the study. Exclusion criteria were prevalence of severe internal illness, and alcohol, drug or nicotine abuse. Diagnosis of AD was based on a history of recurrent flexural eczema, a personal and/or family history of atopy, and clinical criteria of AD as stated by Hanifin and Rajka [14]. Cutaneous involvement, scored according to Costa et al. [7], in the range moderate to marked severity, was $37-67$ points (mean $\pm \mathrm{SD}: 46.9 \pm 10.2$ ) before therapy and $11-55$ points (mean $\pm S D: 27.6 \pm 12.3$ ) at the end of the study.

\section{Test protocol}

Venous blood samples were taken at $7 \mathrm{a} . \mathrm{m}$. and 4 p.m. into EDTAcontaining plastic tubes on day 1 . At 11 p.m. of the same day all patients and controls underwent a $1 \mathrm{mg}$ dexamethasone suppression test to evaluate the integrity of the feedback regulation of the hypothalamus-pituitary-adrenal axis. Post-dexamethasone blood samples were drawn on day 2 as described for day 1 . This procedure was followed by daily oral methylprednisolone administration in both groups at 7 a.m.: $8 \mathrm{mg}$ on days 3 to 6 , and $4 \mathrm{mg}$ on days 7 and 8. On day 8 blood was drawn at 4 p.m. For determination of lymphocyte proliferation on days 1 and 8 , blood samples were collected into prechilled plastic tubes containing EDTA.

\section{Chemicals}

${ }^{3} \mathrm{H}$-Thymidine (specific activity $25 \mathrm{Ci} / \mathrm{mmol}$ ) was purchased from Amersham (Buckinghamshire, UK) and phosphate buffered saline (PBS) from Boehringer (Mannheim, FRG). Con A, PHA, PWM and sodium metrizoate-Ficoll were obtained from Sigma (St. Louis, Mo., USA), and Rotiszint 22 from Roth (Karlsruhe, FRG). The culture medium consisted of RPMI medium (Boehringer, Mannheim, FRG) containing $2 \mathrm{~m} M$ L-glutamate (Biochrom, Berlin, FRG) and $0.1 \mathrm{mg} / \mathrm{ml}$ gentamicin (Biochrom) with $8 \%$ fetal calf serum (Biochrom) added.

\section{Preparation of cells}

A mononuclear cell fraction was prepared under sterile conditions by sodium metrizoate-Ficoll density-gradient centrifugation [3]. Cells were washed twice in $40 \mathrm{ml}$ PBS for $10 \mathrm{~min}$ and incubated for $60 \mathrm{~min}$ at $37^{\circ} \mathrm{C}$ to allow sufficient dissociation of endogenous hormone, followed by a third washing procedure. The final concentration of cells was determined using a Coulter Counter (Model S5, Coulter Electronics, UK). The viability of the cells exceeded $95 \%$ as judged from their ability to exclude trypan blue. Contamination by erythrocytes was $<10 \%$, and by granulocytes and monocytes $<8 \%$, and did not differ between the test days.

\section{Lymphocyte proliferation tests}

Lymphocyte proliferation experiments were performed using plastic microtitre plates with a total volume of $0.22 \mathrm{ml}$. Cells (25000) were incubated in culture medium at $37^{\circ} \mathrm{C}$ in an atmosphere containing $5 \% \mathrm{CO}_{2}$ for $60 \mathrm{~h}$ to evaluate Con $\mathrm{A}$ - and PHA-generated T-cell mitogenesis, and for $130 \mathrm{~h}$ to evaluate PWM-generated B-cell proliferation as well as glucocorticoid-induced inhibition of spontaneous mitogenesis. Concentrations of Con A and PWM of $0.5,1$, $5,10,20,40$, and $50 \mu \mathrm{g} / \mathrm{ml}$ were used to evaluate the dose-response curves, and concentrations of $0.1,0.5,1,2.5,5,10$, and $20 \mu \mathrm{g} / \mathrm{ml}$ PHA were used for the determination of the effects on lymphocyte proliferation. In vitro glucocorticoid effects on mitogen-stimulated lymphocyte proliferation were assessed by increasing dexamethasone (DEX) concentrations from $10^{-10}$ to $10^{-6} \mathrm{M}$. For determination of glucocorticoid effects in vitro, dose-response curves were obtained for concentrations of $1,5,10$, and $40 \mu \mathrm{g} / \mathrm{ml}$ Con A and PWM, and for concentrations of $0.5,1,5$, and $10 \mu \mathrm{g} / \mathrm{ml}$ PHA.

Five hours before ending the incubation period $0.5 \mu \mathrm{Ci}{ }^{3} \mathrm{H}-$ thymidine was added, and incorporated ${ }^{3} \mathrm{H}$-thymidine was subsequently separated from free nucleotide by rapid filtration through Whatman GF/B filters (Nr. 11731) with a Titertek cell harvester by washing with distilled water for $11 \mathrm{~s}$ at room temperature. The filters were transferred into plastic vials and, after the addition of $5 \mathrm{ml}$ of a toluene-based scintillation cocktail (Rotiszint 22 Karlsruhe, FRG), were monitored for tritium in a Beckman LS 5000 TD beta-counter (Munich, FRG) (efficiency about 54\%). All samples were assayed in triplicate with a variation coefficient of $<15 \%$.

\section{Data analysis}

Lymphocyte proliferation was expressed in terms of a stimulation index determined from the ratio of stimulated to unstimulated (baseline) disintegrations per minute. The area under the dose - response curves (AUC) (stimulation index $\times$ lectin concentration) was determined using trapezoidal integration (unit: $\mu \mathrm{g} / \mathrm{ml}$ ). 
DOSE RESPONSE CURVE PATIENTS

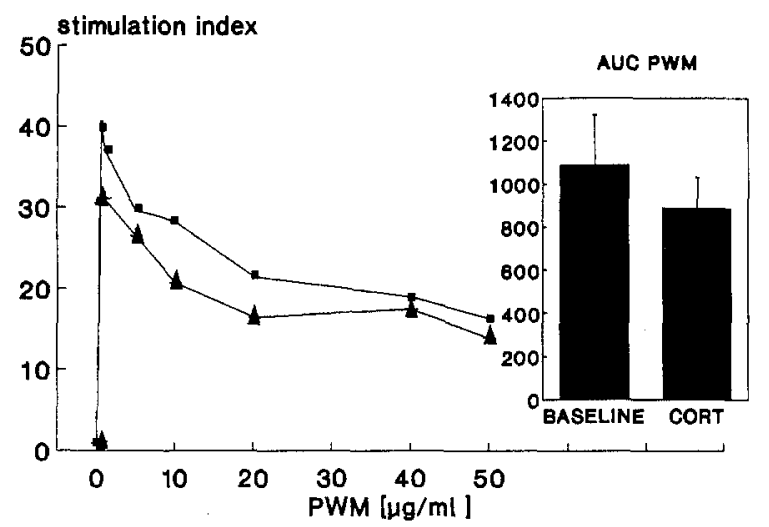

DOSE RESPONSE CURVE CONTROLS

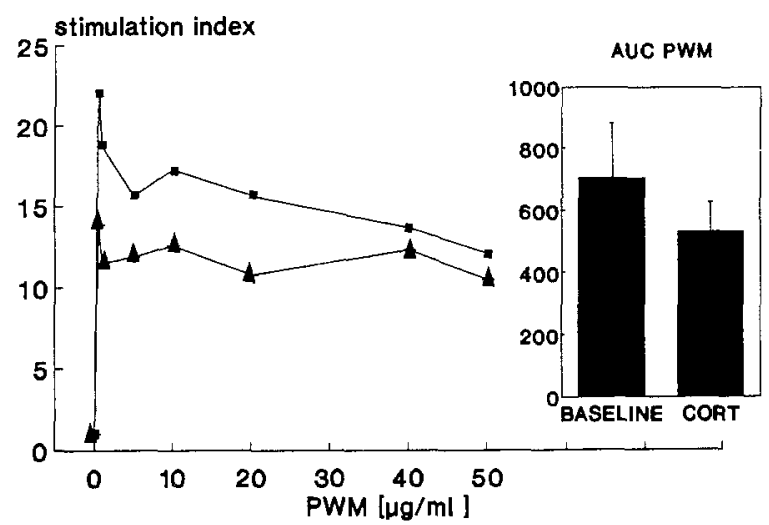

Fig. 2. Mean dose-response curves and AUC of PWM-generated lymphocyte proliferation in patients and controls under baseline conditions ( $\boldsymbol{\square})$ and methylprednisolone treatment $(\boldsymbol{\Delta})$. SEM are omitted for reasons of presentation. The inset shows the mean \pm SEM AUC for the baseline (BASELINE) and methylprednisolone treated $(C O R T)$ conditions in $\mu \mathrm{g} / \mathrm{ml}$. There is no significant difference in the reaction to methylprednisolone treatment in patients and controls

The results are expressed as means $\pm \mathrm{SD}$, and as means $\pm \mathrm{SE}$ in the figures. Comparisons between patients and controls were made using Student's $t$-test, the intra-individual comparisons by the $t$-test for paired samples. All significance levels are two-tailed. Statistical significance was taken as $p<0.05$.

\section{Results}

Increasing concentrations of mitogens added to lymphocytes from patients and controls resulted in dose-response curves with maximal stimulation of lymphocyte proliferation at $10 \mu \mathrm{g} / \mathrm{ml}$ Con A (Fig. 1) and at $1 \mu \mathrm{g} / \mathrm{ml}$ PWM (Fig. 2). PHA-generated mitogenesis was maximal at concentrations of $10-20 \mu \mathrm{g} / \mathrm{ml}$ (Fig. 3). There was no shift of the maxima in the dose-response curves in patients and controls after glucocorticoid administration (Figs. $1-3$ ). The AUC after stimulation with Con A, PHA or PWM did not differ significantly between patients and controls (Figs. 1-3) under baseline conditions.
DOSE RESPONSE CURVE PATIENTS

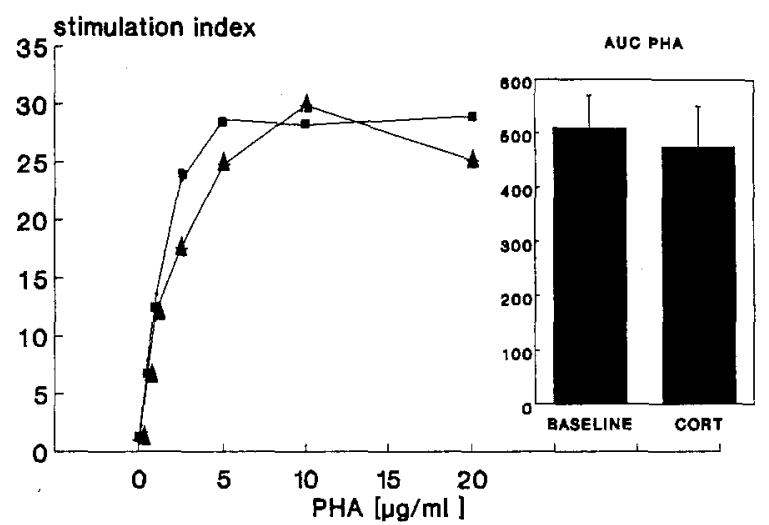

DOSE RESPONSE CURVE CONTROLS

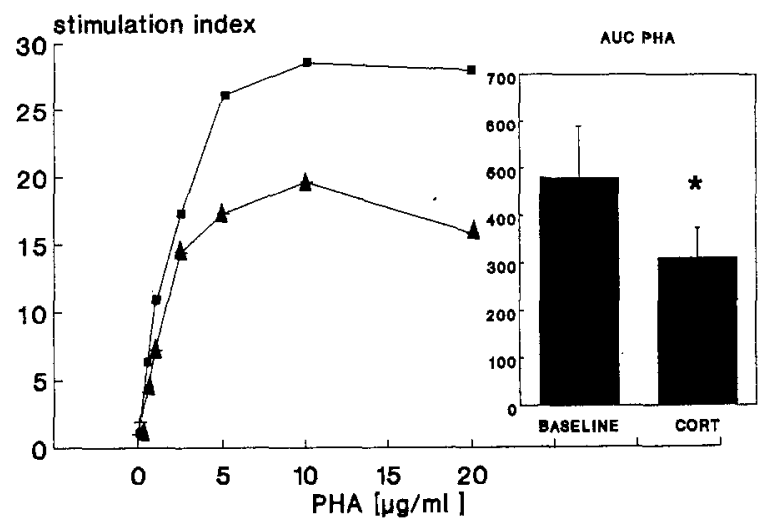

Fig. 3. Mean dose-response curves and AUC of PHA-generated lymphocyte proliferation in patients and controls under baseline conditions ( $\boldsymbol{\square})$ and methylprednisolone treatment $(\boldsymbol{\Delta})$. SEM are omitted for reasons of presentation. The inset shows the mean $\pm \mathrm{SEM}$ AUC for the baseline (BASELINE) and methylprednisolone treated $(C O R T)$ condition in $\mu \mathrm{g} / \mathrm{ml}$. Baseline and methylprednisolone conditions differ significantly in controls only

Systemic glucocorticoid administration resulted in a significant reduction in Con A-induced blastogenesis $\left(\mathrm{AUC}_{\mathrm{ConA}}\right)$ in both groups $(p<0.04)$ (Fig. 1), whereas PHA-stimulation of lymphocytes resulted in a significant reduction in blastogenesis $\left(\mathrm{AUC}_{\mathrm{PHA}}\right)$ after glucocorticoid administration in the controls only $(p<0.03)$ (Fig. 3). The differences in $\mathrm{AUC}_{\mathrm{PWM}}$ in patients and controls prior to and after glucocorticoid treatment did not reach statistical significance (Fig. 2).

Dexamethasone administered in vitro had a pronounced suppressive effect on Con A and PHA doseresponse curves in patients and controls at baseline and under corticoid treated conditions (Fig. 4a, b). However, in vivo pretreatment with methylprednisolone further decreased the in vitro suppression of $\mathrm{AUC}_{\mathrm{Con} \mathrm{A}}$ and $\mathrm{AUC}_{\mathrm{PHA}}$ by dexamethasone in the controls $(p<0.05)$, but not in the patients (Fig. $4 \mathrm{a}, \mathrm{b}$ ). In contrast, no consistent effect of the corticoid pretreatment on the in vitro response to dexamethasone could be observed with regard to PWMgenerated B-cell proliferation (Fig. 4c). 

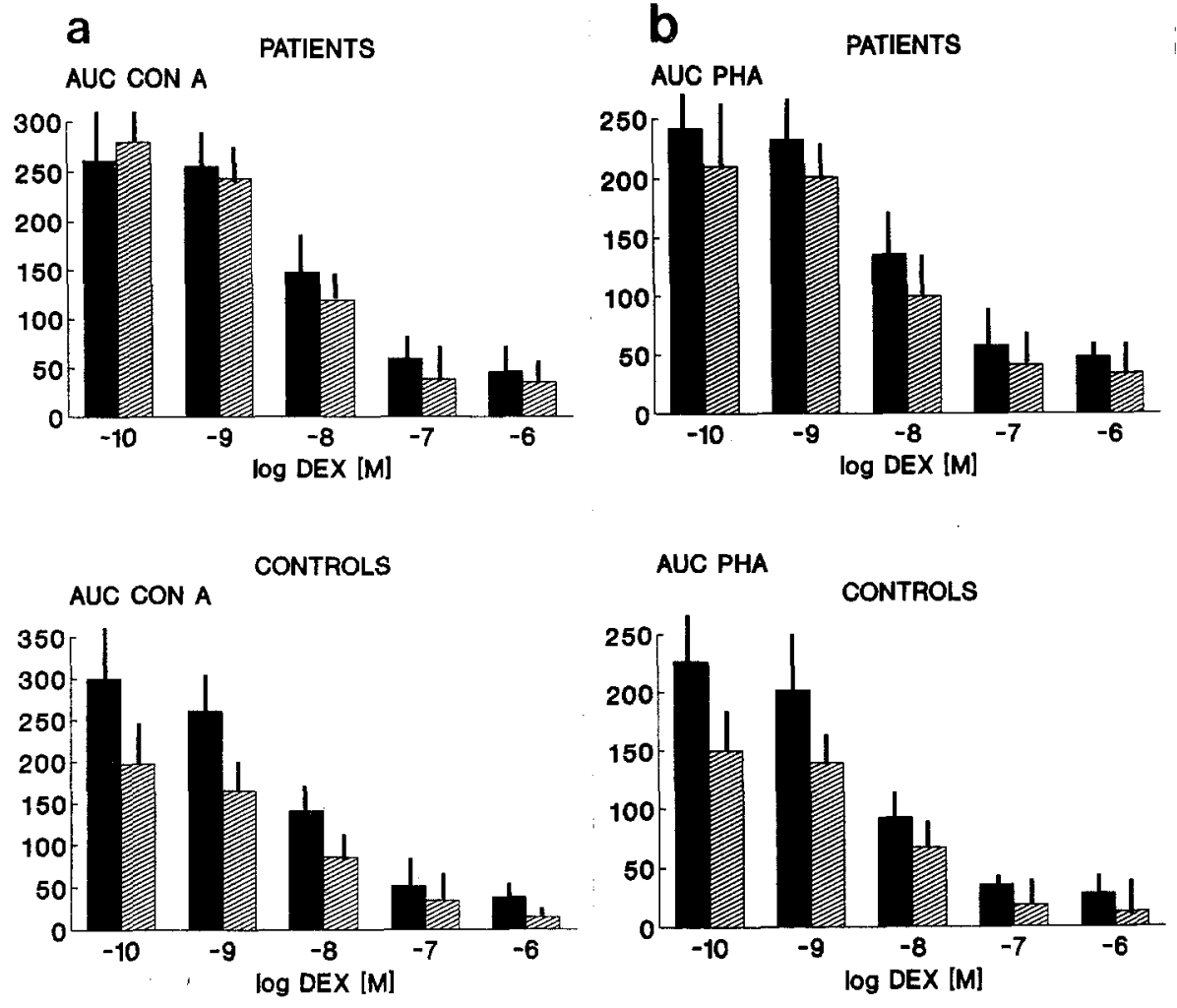
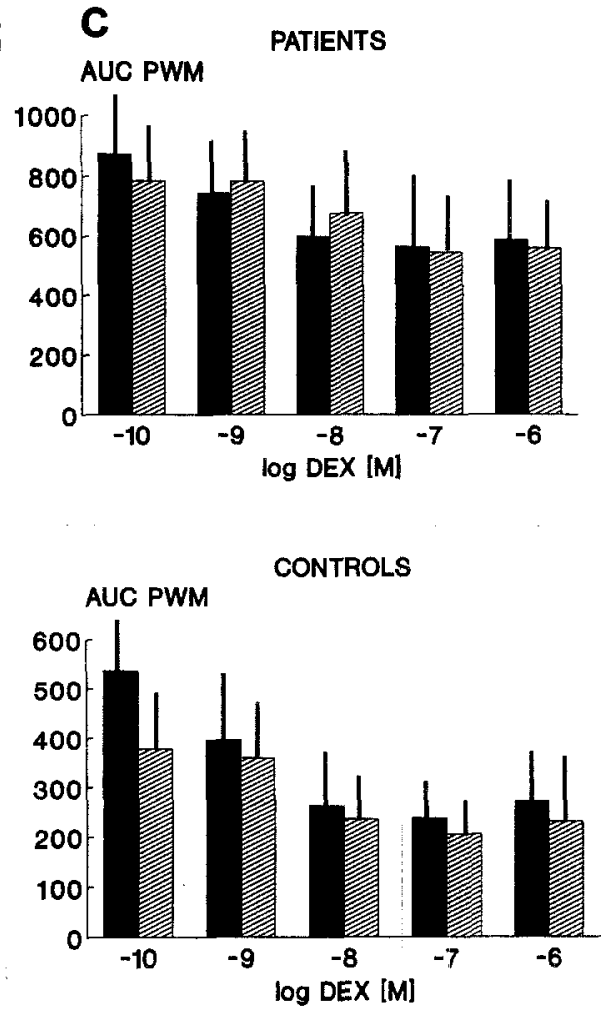

Fig. 4a-c. Mitogen stimulation after administration of different dexamethasone $(D E X)$ concentrations in vitro in untreated (solid bars) and corticoid-treated (hatched bars) patients and controls. a Mean \pm SEM AUC of Con A-generated lymphocyte proliferation in $\mu \mathrm{g} / \mathrm{ml}$. A significantly greater suppression occurred in controls than in patients after methylprednisolone pretreatment. b Mean \pm SEM AUC of PHA-generated lymphocyte proliferation in $\mu \mathrm{g} / \mathrm{ml}$. A significantly greater suppression occurred in controls than in patients after methylprednisolone pretreatment. c Mean \pm SEM AUC of PWM-generated lymphocyte proliferation in $\mu \mathrm{g} / \mathrm{ml}$. No significant effect of methylprednisolone pretreatment was found in patients and controls

\section{Discussion}

The normal response to Con A, PHA and PWM found in our patients with $\mathrm{AD}$ is in accordance with previous reports $[23,32]$ which could not confirm findings of impaired leucocyte proliferation in $\operatorname{AD}[5,18,20]$. The decreased Con $\mathrm{A}$-induced blastogenesis in patients and controls after the administration of glucocorticoids in vivo and in vitro may be due to the suppressive effects of glucocorticoids on T-cell mitogenesis [8, 16, 28, 34].

Corticosteroid effects on PHA-induced blastogenic response have been found to be variable [8]. This variability has been explained by the observation that glucocorticoids can shift the peak of the PHA doseresponse curve to higher concentrations [8], but this could not be confirmed in the present study. Since the suppression of PHA responsiveness by glucocorticoids is dose related, it could be hypothesized that the suppression only in the controls of $\mathrm{AUC}_{\mathrm{PHA}}$ after methylprednisolone therapy is due to a higher sensitivity of normal lymphocytes to glucocorticoids. This hypothesis is supported by the observation that higher glucocorticoid concentrations, as obtained in vitro, also produced a sufficient suppression of $\mathrm{AUC}_{\mathrm{PHA}}$ in patients. Thus, the significantly greater suppression of Con A- and PHA-induced blastogenesis in vitro in the controls after methylprednisolone treatment points to a subtle in vivo resistance of leucocytes to glucocorticoids in patients with AD.

Elevated IL-2 receptor levels in AD have recently been described [4] and glucocorticoids are known to reduce both IL-2 receptor sites and IL-2 production [4, 33]. Therefore, impaired suppression of these receptors by glucocorticoids in AD may be the reason for the higher lectin-induced proliferation rate of lymphocytes following glucocorticoid therapy in comparison with the controls.

PWM-induced blastogenesis measured after 5 days of culture has been shown mainly to reflect B-cell proliferation $[2,8,15]$ and has been observed to be relatively refractory to the suppressive effect of glucocorticoids [2, $8,15]$. These findings are in accordance with our results in patients and controls. Our data show a lowered suppression of some proliferation parameters of mononuclear leucocytes after in vivo administration of methylprednisolone, while the in vitro effects of dexamethasone appear to be normal. These findings together with recently reported alterations in glucocorticoid receptor pharmacology in $\mathrm{AD}$ [27] suggest a decreased biological efficiency of methylprednisolone on lymphocytes in vivo, the origin of which remains to be elucidated.

Acknowledgements. We are indebted to Ms. S. Nistelweck for excellent technical assistance. The Johannes and Frieda Marohn Stiftung, 
University of Erlangen-Nürnberg, provided financial support of this study.

\section{References}

1. Beran D, Kossard S, Freeman S, Vasak E, Paver K, Penny R (1986) Immune mechanisms in atopic dermatitis: studies and hypothesis. Aust J Dermatol 27:112-117

2. Blomgren H, Anderson B (1976) Steroid sensitivity of the PHA and PWM responses in vitro. Exp Cell Res 97:233-240

3. Boyum A (1968) Separation of leukocytes from blood and bone marrow. Scand J Clin Lab Invest 21:97-107

4. Colver BG, Symons JA, Duff GW (1989) Soluble interleukin 2 receptor in atopic eczema. Br Med J 298:1426-1428

5. Cooper KD, Kazmierowski JA, Wüpper KD, Hanifin JM (1983) Immunoregulation in atopic dermatitis: functional analysis of $\mathrm{T}-\mathrm{B}$ cell interactions and the enumeration of $\mathrm{Fc}$ receptor-bearing cells. J Invest Dermatol 80:139-145

6. Cormane RH, Hamerlinch F, Husz S (1975) B and T lymphocytes in certain varieties of dermatitis. Ann NY Acad Sci $254: 592-599$

7. Costa C, Rilliet A, Nicolet M, Saurat JH (1989) Scoring atopic dermatitis: the simpler the better? Acta Derm Venereol (Stockh) $69: 41-45$

8. Cupps TR, Fauci AS (1982) Corticosteroid-mediated immunoregulation in man. Immunol Rev 65:133-155

9. Fauci AS, Dale DC (1975) Alternate-day prednisone therapy and human lymphocyte populations. J Clin Invest 55: 22-32

10. Fauci AS, Dale DC (1975) The effect of hydrocortisone on the kinetics of normal human lymphocytes. Blood 46:235-243

11. Faulstich ME, Williamson DA, Duchmann EG, Conerly SL, Brantley PP (1985) Psychophysiological analysis of atopic dermatitis. J Psychosom Res 29:415-417

12. Gillis S, Crabtree GR, Smith KA (1979) Glucocorticoid-induced inhibition of T-cell growth factor production: I. The effect on mitogen-induced lymphocyte proliferation. J Immunol 123:1624-1631

13. Grove GL, Reid JG, Forbes IJ (1975) Humoral and cellular immunity in atopic eczema. Br J Dermatol 92:611-617

14. Hanifin JM, Rajka G (1980) Diagnostic features of atopic dermatitis. Acta Derm Venereol Suppl (Stockh) 92:44-47

15. Heilmann DH (1972) Failure of hydrocortisone to inhibit blastogenesis by pokeweed mitogen in human leukocyte cultures. Clin Exp Immunol 11:393-403

16. Heilmann DH, Gambrill M, Leichner JP (1973) The effect of hydrocortisone on the incorporation of tritiated thymidine by human blood lymphocytes cultured with phytohaemagglutinin and pokeweed mitogen. Clin Exp Immunol 15:203-212

17. Heubeck B, Schönberger A, Hornstein OP (1988) Sind Verschiebungen des zirkadianen Cortisolrhythmus ein endokrines Symptom des endogenen Ekzems? Hautarzt 39:12-17

18. Hwang KC, Fikrig SM, Friedman HM, Gupta S (1985) Deficient concanavalin-A-induced suppressor-cell activity in patients with bronchial asthma, allergic rhinitis and atopic dermatitis. Clin Allergy 15:67-72
19. Juhlin L, Johansson SGO, Bennich H, Högman C, Thyresson $\mathrm{N}$ (1969) Immunoglobulin $\mathrm{E}$ in dermatoses. Arch Dermatol 100:12-16

20. Kapp A, Gillitzer R, Kirchner H, Schöpf E (1987) Production of interferon and lymphoproliferative response in whole blood culture derived from patients with atopic dermatitis. Arch Dermatol Res 279:S55-S58

21. van de Kerkhof PCM (1982) Plasma aldosterone and cortisol levels in psoriasis and atopic dermatitis. $\mathrm{Br} \mathrm{J}$ Dermatol $106: 423-428$

22. Leung DYM, Rhodes AR, Geha RS (1981) Enumeration of T cell subsets in atopic dermatitis using monoclonal antibodies. J Allergy Clin Immunol 67:450-454

23. Martinez JD, Santos J, Stechschulte DJ, Abdou NI (1979) Nonspecific suppressor cell function in atopic dermatitis. $\mathrm{J}$ Allergy Clin Immunol 64:485-490

24. Mendelsohn J, Multer MM, Bernheim JL (1977) Inhibition of human lymphocyte stimulation by steroid hormones: cytokinetic mechanisms. Clin Exp Immunol 27:127-134

25. Rogge JL, Hanifin JM (1976) Immunodeficiencies in severe atopic dermatitis. Arch Dermatol 112:1391-1394

26. Rola-Pleszczynski M, Blanchard R (1981) Abnormal suppressor cell function in atopic dermatitis. J Invest Dermatol $76: 279-283$

27. Rupprecht M, Rupprecht R, Koch U, Kornhuber J, Wodarz N, Riederer P, Hornstein OP (1991) Elevated glucocorticoid receptor concentrations before and after glucocorticoid treatment in atopic dermatitis. Dermatologica (in press)

28. Saxon A, Stevens RH, Ramer SJ, Clements PJ, Yu DTY (1977) Glucocorticoids administered in vivo inhibit human suppressor $\mathrm{T}$ lymphocyte function and diminish $\mathrm{B}$ lymphocyte responsiveness in in vitro immunoglobulin synthesis. J Clin Invest $61: 922-930$

29. Schöpf E, Kapp A, Kim CW (1978) T-cell function in atopic dermatitis - controlled examination of concanavalin A doseresponse relations in cultured lymphocytes. Arch Dermatol Res $262: 37-44$

30. Silny W, Laczowska M (1987) Lymphocyte subpopulations in patients with atopic dermatitis. Dermatol Monatsschr 173: $724-729$

31. Snyder DS, Unanue ER (1982) Corticosteroids inhibit murine macrophage Ia expression and interleukin-1 production. J Immunol 129:1803-1805

32. Valverde E, Vich JM, Huguet J, García-Calderón JV, GarcíaCalderón PA (1983) An in vitro study of lymphocytes in patients with atopic dermatitis. Clin Allergy 13:81-88

33. Walker KB, Potter JM, House AK (1987) Interleukin 2 synthesis in the presence of steroids: a model of steroid resistance. Clin Exp Immunol 68:162-167

34. Webel ML, Ritts RE (1977) The effects of corticosteroid concentrations on lymphocyte blastogenesis. Cell Immunol 32:287292 